\title{
1 China's soil and groundwater management challenges: lessons from the 2 UK's experience and opportunities for China
}

Frédéric Coulon ${ }^{1}$, Kevin Jones ${ }^{2}$, Hong $\mathrm{Li}^{2}$, Qing $\mathrm{Hu}^{3}$, Jingyang $\mathrm{Gao}^{3}$, Fasheng $\mathrm{Li}^{4}$, Mengfang $\mathrm{Chen}^{5}$, Yong-Guan Zhu ${ }^{6}$, Rongxia Liu ${ }^{7}$, Ming Liu ${ }^{8}$, Kate Canning ${ }^{9}$, Nicola Harries ${ }^{10}$, Paul Bardos $^{11}$, Paul Nathanail ${ }^{12}$, Rob Sweeney ${ }^{10}$, David Middleton ${ }^{13}$, Maggie Charnley ${ }^{13}$, Jeremy Randall $^{14}$, Martin Richell ${ }^{14}$, Trevor Howard ${ }^{15}$, Ian Martin ${ }^{15}$, Simon Spooner ${ }^{16}$, Jason Weeks ${ }^{1}$, Mark Cave ${ }^{17}$, Fang Yu ${ }^{18}$, Fang Zhang ${ }^{19}$, Ying Jiang ${ }^{1}$, Phil Longhurst ${ }^{1}$, George Prpich ${ }^{1}$, Richard Bewley $^{20}$, Jonathan Abra ${ }^{21}$, and Simon Pollard ${ }^{1}$

${ }^{1}$ Cranfield University, School of Energy, Environment and Agrifood, Cranfield, MK430AL, UK

${ }^{2}$ Lancaster Environment Centre, Lancaster University, LA1 4YQ, UK

${ }^{3}$ Engineering Innovation Centre, South University of Science and Technology of China, 1088 Xue Yuan Da Dao, Nanshan, Shenzhen, Guangdong, 518055China

${ }^{4}$ Department of Soil Pollution Control, Chinese Research Academy of Environmental Sciences (CRAES), 8 Dayangfang BeiYuan Road., Chaoyang District,Beijing 100012,China

${ }^{5}$ Institute of Soil Science, Chinese Academy of Science (ISSAS), 71 East Beijing Road, Nanjing, 210008, China

${ }^{6}$ The Institute of Urban Environment (IUE), Chinese Academy of Sciences (CAS), 1799 Jimei Road, Xiamen 361021 China

${ }^{7}$ The Administrative Centre for China's Agenda21 (ACCA21), 8 Yuyuantan Nanlu, Haidian District, Beijing 100038, China

${ }^{8}$ Department of Science, Technology \& Innovation, British Consulate-General Guangzhou, 5 Zhujiang Road West, Zhujiang New Town, Guangzhou, 510623 China

${ }^{9}$ Arup, Energy and Resources, $6^{\text {th }}$ floor, 3 Piccadilly place, Manchester M3 1 BN, UK

${ }^{10} \mathrm{CL}$ :AIRE, 32 Bloomsbury Street, London, WC1B 3QJ, UK

${ }^{11}$ University of Brighton, Environment and Technology, Moulsecoomb, Brighton, BN2 4GJ, UK

${ }^{12}$ School of Geography, The University of Nottingham, University Park, Nottingham, NG7 2RD, UK \& Land Quality Management Ltd, University of Innovation Park, Sir Colin Campbell Bldg, Nottingham NG7 2TU, UK

${ }^{13}$ Department for Environment, Food and Rural Affairs (DEFRA, UK), Nobel House, 17 Smith Square, London, SW1P 3JR, UK

${ }^{14} \mathrm{RAW}$, Randall and Walsh Associated Limited, 339 Yorktown road, Sandhurst GU47 0PX, UK

${ }^{15}$ Environment Agency (England), Horizon House, Deanery Road, Bristol, BS1 5AH, UK

${ }^{16}$ Atkins, Water Ground and Environment, Epsom, KT18 5BW, UK and Nottingham University, Ningbo, 199 Taikang E Rd, Yinzhou, Ningbo, Zhejiang, 315100 China

${ }^{17}$ British Geological Survey, Keyworth, Nottingham, NG12 5GG, UK

${ }^{18}$ Chinese Academy for Environmental Planning, 8 Dayangfang BeiYuan Road.,Chaoyang District, Beijing 100012,China

${ }^{19}$ School of Environment, Tsinghua University, Haidian, Beijing, 100084, China

${ }^{20} \mathrm{AECOM}$, New York St, Manchester, Lancashire M1, United Kingdom, UK

${ }^{21}$ KTN, Innovation Suite, The Heath, Runcorn, Cheshire WA7 4QX 
There are a number of specific opportunities for UK and China to work together on contaminated land management issues as China lacks comprehensive and systematic planning for sustainable risk based land management, encompassing both contaminated soil and groundwater and recycling and reuse of soil. It also lacks comprehensive risk assessment systems, structures to support risk management decision making, processes for verification of remediation outcome, systems for record keeping and preservation and integration of contamination issues into land use planning, along with procedures for ensuring effective health and safety considerations during remediation projects, and effective evaluation of costs versus benefits and overall sustainability. A consequence of the absence of these overarching frameworks has been that remediation takes place on an ad hoc basis. At a specific site management level, China lacks capabilities in site investigation and consequent risk assessment systems, in particular related to conceptual modelling and risk evaluation. There is also a lack of shared experience of practical deployment of remediation technologies in China, analogous to the situation before the establishment of the independent, non-profit organisation CL:AIRE (Contaminated Land: Applications In Real Environments) in 1999 in the UK. Many local technology developments are at lab-scale or pilot-scale stage without being widely put into use. Therefore, a shared endeavour is needed to promote the development of technically and scientifically sound land management as well as soil and human health protection to improve the sustainability of the rapid urbanisation in China.

Keywords: Contaminated land management, rapid urbanisation, risk assessment, China, UK

\section{China's rapid urbanisation and the contaminated land debate}

China's fast urbanisation, along with huge expansion of its manufacturing industry over the last three decades, have brought great wealth and transformed the lives of Chinese people. At China's current urbanisation rate, it is estimated that 350 million people, almost 6 times the current population of the United Kingdom, will be added to its total urban population by 2025 (Woetzel et al., 2009). As cities continue to expand, many older industrial facilities along the edge of, or within, the city boundaries are being relocated or closed, leaving behind derelict, underused and abandoned land contaminated by the former industrial activities. These sites can be valuable land for re-development, but require special intervention to bring them back into beneficial use. At the same time, the continuous outward shift of urban boundaries and 
the expansion of territorial jurisdictions of cities, primarily through the expropriation of surrounding rural land and its integration into urban areas, means that land use patterns have changed significantly over the last few decades (World Bank Organisation, 2014). These prevailing land use changes are reflected in three key environmental issues (Figure 1) that need to be addressed:

1. the rehabilitation of contaminated post-industrial urban sites that may be re-used for housing or amenity;

2. the clearing up of legacy mining and industrial sites outside cities, to prevent further contamination and/or to return to ecological or agricultural function;

3. the decontamination of farmland that is affected by legacy contamination, from the uncontrolled spreading of industrial waste, use of contaminated water for irrigation, atmospheric deposition or dumping of contaminated soils from urban or industrial areas.

Re-zoning to relocate industrial facilities away from residential areas, to segregate manufacturing from where people live, and the reuse of redundant sites for residential, retail and commercial land uses mean that China is potentially a strong market for solutions and services in contaminated land characterisation, assessment and remediation. There are several reasons for this: (1) avoiding the use of scarce Greenfield land resources; (2) mitigating the legacy impacts of contamination for both the sites and their locality; and (3) creating new opportunities for land use for business, housing and renewables such as energy, but also for green infrastructure, amenity and leisure; and (4) equally, if legacy of contaminated land remained untouched due to legal concerns or lack of financial resources, or not properly remediated, they can present a serious threat to public health and the environment and become a barrier to local and national economic development. For example, creation of new urban parkland may have substantial benefits on the liveability of cities, the value of its land and the health of its residents.

Although the scale of China's urbanisation and the number of growing large metropolitan regions where this urbanisation is concentrated are globally unprecedented, the issues of urban transformation and associated issues of contaminated land are not novel and unique (OECD, 2010). For example, the UK has already gone through this urbanisation and industrial restructuring process and over the past 40 years has developed pragmatic and effective policy and practices to manage this land contamination legacy. These practices have evolved over time, due to different drivers and needs (Figure 2). They continue to help return 
many thousands of hectares of land to beneficial use. Such experience can help inform Chinese decision makers.

112

\section{China's developing prioritisation and policies for soil and water and the scale of the challenge}

China is starting to release details of its $13^{\text {th }}$ five-year plan, where a number of environmental challenges are addressed, including contaminated land which has again been highlighted as an immediate priority (Figure 1). Under China's current $12^{\text {th }}$ Five-Year Plan, the Ministry of Environmental Protection (MEP) has earmarked 30 billion RMB from central finances (equivalent to $£ 3 \mathrm{bn}$ ) to support national land remediation projects. Indeed, in 2013 the Chinese State Council acknowledged the environmental industry as a pillar for China's future development (Bloomberg BNA, 2015). The environmental industry is expected to grow by $15 \%$ annually, generating a turnover of 4.5 trillion RMB (equivalent to $£ 458 \mathrm{bn}$ ) in 2015 .

The $13^{\text {th }}$ Five-Year Plan also places a greater responsibility on companies to manage their environmental impacts and creates a much greater awareness within industry of its responsibilities. According to the MEP, the groundwater tested in 100 cities across China was not suitable for drinking water supply. The Ministry of Water Resources reported that $40 \%$ of China's rivers were classified as seriously polluted in 2011 , of which $20 \%$ were so polluted that their water quality was rated too toxic for human contact (Hu et al., 2014). The MEP is currently drafting a Clean Water Action Plan to address pollution of surface water resources and to ensure safe drinking water. Industrial wastewater treatment will be one of the priorities. The National Groundwater Contamination Prevention and Remediation Plan calls for a 34.7 billion RMB (equivalent to £3.6bn) investment through 2020 (export.gov, 2014). Through 2015 the State Council is accelerating drafting the "Soil Environmental Protection Law" and the Ministry for Environmental Protection (MEP) is required to produce a Soil Pollution Prevention \& Remediation Action Plan. These should help to address some of the barriers to remediation taking place, establish standards and assign supporting government funding.

China's first nationwide soil quality survey released by the MEP and the Ministry of Land Resources in April 2014 highlighted the significant challenges China is facing to maintain and restore soil function and quality (MEP \& MLR, 2014). For the 6.3 million square kilometres $\left(\mathrm{km}^{2}\right)$ of surveyed land, it was estimated that $16 \%$ of the country's soil was polluted, including $19 \%$ of farmland (Figure 3). Among the sites where soil was contaminated, $83 \%$ were impacted by inorganics (see Table 1 for the main pollutants in soils 
and groundwater). Extrapolation of the soil sampling survey work suggests the total area of arable land contaminated with heavy metals is 20 million hectares, accounting for $1 / 6^{\text {th }}$ of the total arable land in China. While there may be some question marks over the reliability of this extrapolation, it does seem clear that there are substantial areas potentially affected.

Regarding geographical distribution, soil contamination in southern China is more important than northern China and the primary concern is metal contamination (Hu et al., 2014; MEP and MRL, 2014). The Yangtze River Delta, Pearl River Delta, and old industrial areas in north eastern China have significant soil contamination issues, while the south western and southern middle regions of China have been largely impacted by metal contamination (Hu et al., 2014; Circle of Blue, 2014).

Government legislation has just begun to lay the foundation for market growth, which will bring a wide range of opportunities for business, although soil protection and remediation are still in the early stages of development (Financial Times, 2015). Currently the Chinese government has planned to close around 500 industrial sites involved in soil pollution and would spend 3\% of the total economic output of Shanghai that ranges around 2220 billion RMB (equivalent to $£ 230 \mathrm{bn}$ ) which suggests there is a strong potential for growth in the rate of remediation and establishing strong technical capabilities and delivery (Ken Research, 2009).

The National Soil Pollution Prevention and Treatment Action Plan of China was approved by the MEP in early 2014 and is awaiting further approval from the central government before being released to the public. Soil and groundwater protection are inseparable cycles. The MEP has issued the National Groundwater Contamination Pollution Prevention and Remediation Plan (2011-2020) which allocated 37 billion RMB (equivalent to $£ 3.8 \mathrm{bn}$ ) to support the implementation of new measures. With regulatory developments, it is expected that the soil and groundwater remediation markets will grow significantly in the coming years, especially under two sub-sectors: arable land and brownfield sites in urban areas (Dora Chiang and Gu, 2015). The People's Daily newspaper has suggested that as many as 300,000 brownfield sites are in need of treatment before redevelopment. Dora Chiang and Gu (2015) further reported that the soil remediation market size is estimated to reach $£ 77 \mathrm{bn}$ by 2018 and up to $£ 142$ bn by 2020 .

\section{Setting the soil regulatory framework, key to defining management of contaminated land}

In 2014 the MEP published new national technical guidelines regarding environmental 
investigation, risk assessment, monitoring and remediation (Dora Chiang and $\mathrm{Gu}, 2015$ ), while the 1995 national soil standards are currently under revision and are expected to cover industrial and agricultural sites (Dora Chiang and $\mathrm{Gu}, 2015$ ). However, Chinese agencies recognise there is still a need for support to develop and enforce a comprehensive legislative framework and funding systems, as well as establishing a mature characterisation, assessment and remediation application and technology market (Figure 1). In common with other emerging contaminated land markets, China stands to benefit from technical collaboration and knowledge exchange.

Recently the sustainable development policy agenda, notably the newly adopted Sustainable Development Goals (SDGs, 2015), is resulting in new ways of thinking in China about risk, technology and decision-making. Increasingly, approaches to site remediation are being scrutinized by reference to their full life-cycle costs, with environmental, social, economic and technical factors being considered in developing risk management strategies. The environmental industry, professional specialists and environmental regulators need to reconsider how these broader aspects can be incorporated into decision making for contaminated land management.

Technical collaboration in the development of risk based approaches to contaminated land characterisation, assessment and remediation will lead to substantial benefits for China and the UK (Figure 1). At the urban planning stage, China needs support to develop comprehensive and systematic planning in soil protection and risk management. This needs to be further supported by a comprehensive risk assessment system, including postrestoration monitoring and safety and human health assessment and a system of recording site ownership and land quality. With out-dated site investigation technology and inappropriate remediation technology choices at many site restoration projects have resulted either in secondary pollution or otherwise incomplete outcomes. This has been attributed in large to the absence of an integrated supporting framework of guidance and experience to support remediation decision making in China.

Inexperienced site owners, developers and regulators sometimes have unrealistic expectations of the objective, cost and timeframe of remediation, which makes it difficult for a remediation project to be properly designed and implemented, particularly for large, complex sites. In addition, risk management and remediation implementation are seldom integrated into the planning and redevelopment of contaminated sites across China. A clearer framework for the assignment of liabilities and responsibilities for remediation work, and a risk-based 
approach to assessing the required standards - as well as understanding the costs and impacts of reaching these - is required, together with systematic monitoring and investigation of sites for the specification of works. Together these gaps mean that China has the opportunity to incentivise sound commercial rationales to drive the investment needed to bring its brownfield land back into use, manage its land contamination problems and harness the opportunities these measures would generate. It will further help to establish confidence in brownfield land management and investment.

\section{Learning from and adapting the UK's experiences}

The UK has established a comprehensive frameworks built around preventing current activities from causing pollution and risk-based management of legacy pollution. After various lessons learnt, the UK now enjoys mature solutions to matters such as qualification, approval of land transfer and definition of the responsible party for remediating polluted land. The UK has a track record of sustainable, integrated remediation strategies and many successful examples of remediation of polluted land. Additionally, the UK has established a way of accrediting the competence and independence of laboratories that are able to provide unbiased and accurate analyses of soil, water and other media. This combination of policy frameworks and experienced expertise delivers a cost efficient, effective and ultimately transferable way of managing land contamination legacies.

The risk-based approach of the UK's contaminated land legislative regimes (non-prescriptive and pragmatic) has further allowed more innovative, cost effective and sustainable approaches to be applied than elsewhere in the world. Thus, both the legal frameworks and the solutions that have been developed are of interest to China as it seeks to address its legacy of contaminated land and to reuse its urban spaces (Figure 1). The UK also has experience with designing and validating cost-effective risk management solutions as well as implementing good risk communication to ensure wider acceptance of the process and its results. The risk based contaminated land management paradigm has become a central point of reference for much of the supporting science and the basis of public policy and environmental regulation on contaminated land in the UK. Sharing this would benefit China in developing and then implementing its own contaminated land management framework.

Both the UK and China have strong track records of academic research on land remediation. However, in terms of policy framework and experience of contaminated land risk assessment 
and remediation, China is still in the early stages. Hence, this is the time at which discussion and joint actions will provide effective solutions to the environmental challenge China is seeking to address. Specifically, emphasis on the developments in risk assessment, remediation, impacts on human health and the policy and regulatory frameworks is needed. This can be facilitated by:

- Establishing channels between China and the UK that will facilitate mutual learning and understanding on contaminated land management issues

- Creating a constructive broad-based partnership that involves civil society, regulators, the scientific community and business interests

- Promoting the development of a framework that connects research, field applications, and industrial investment, to maximise and sustain contaminated land management and redevelopment

- Establishing common framework to protect human health and the environment from chemical hazards

- Building upon existing work to create a progressive alliance and improve alignment on contaminated land management and sustainable development related issues in international fora with a view to attain policy and practice convergence and joint action

- Promoting business opportunities between China and UK along with technical cooperation

Acknowledgements: The authors acknowledge the financial support from the Foreign Common Office's Prosperity Fund programme (project 15SU32).

\section{References}

Bloomberg BNA, (2014) China Outlines Environmental Action in 'War' on Air, Water and Soil Pollution" available at http://www.bna.com/china-outlines-environmental$\underline{\mathrm{n} 17179882762 /}$ (accessed on 15 October 2015)

Townsend M., Yang Z, and Ivanova N. (2011) Infographic: Map of Pollution Levels in China's Major River Basins, Circle of Blue, available at http://www.circleofblue.org/waternews/2011/world/infographic-map-of-pollution-levels-inchinas-major-river-basins/ (accessed on 11 January 2016)

Dora Chiang S-Y., Gu Q. (2015) Brownfield site remediation technology: overview, trends and opportunities in China. Remediation Journal 25: 85-99 
Ellis D.E. and Hadley P.W. (2009) Sustainable remediation White Paper - Integrating sustainable principles, practices and metrics into remediation projects. Remediation Journal 19: $5-114$

Export.gov. (2014) Environmental Technology http://export.gov/china/doingbizinchina/leadingsectors/eg cn 081024.asp (accessed on 15 October 2015)

Financial Times (2015) Chinese environment: ground operation http://www.ft.com/cms/s/0/d096f594-4be0-11e5-b558-8a9722977189.html (accessed on 2 September 2015)

Hu H., Jin Q., Kavan P. (2014) A study of heavy metals pollution in China: current status, pollution-control policies and countermeasures. Sustainability, 6: 5820-5338

Ken Research (2015) China Soil Treatment Market Outlook to 2019 - Expansion of branded players and agrochemical formulants to drive growth, KR325, June 2015, 171 pp https:/www.kenresearch.com/agriculture-food-beverages/agriculture-industry/china-soiltreatment-market-research-report/651-104.html (accessed on 11 November 2015)

Ministry of Environmental Protection and Ministry of Land and Resource of the People's Republic of China (MEP and MLR). (2014). The Bulletin of Nationwide Soil Pollution Status Survey. April 14, 2014. Index No. 000014672/2014-00351.

Sustainable Development Knowledge platform (2015) Open working Group proposal for Sustainable Development goals available at: https://sustainabledevelopment.un.org/content/documents/1579SDGs\%20Proposal.pdf (accessed on15 October 2015)

OECD, 2010. Trends in urbanisation and urban policies in OECD countries: what lessons for China? doi:10.1787/9789264092259-en 219 pages (available at http://www.oecdilibrary.org/urban-rural-and-regional-development/trends-in-urbanisation-and-urban-policiesin-oecd-countries_9789264092259-en)

Woetzel J., Mendoca L., Devan J., Negri S., Hu Y., Jordan L., Li X., Maasry A., Tsen G. and Yu F. (2009). Preparing for China's urban billion, McKinsey Global Institute, March 2009, $540 \mathrm{pp}$

World Bank, China's urbanization and land: a framework for reform. Chapter 4. available at https://www.worldbank.org/content/dam/Worldbank/document/EAP/China/Urban-ChinaSRs4-7.pdf (accessed on 15 October 2015) 


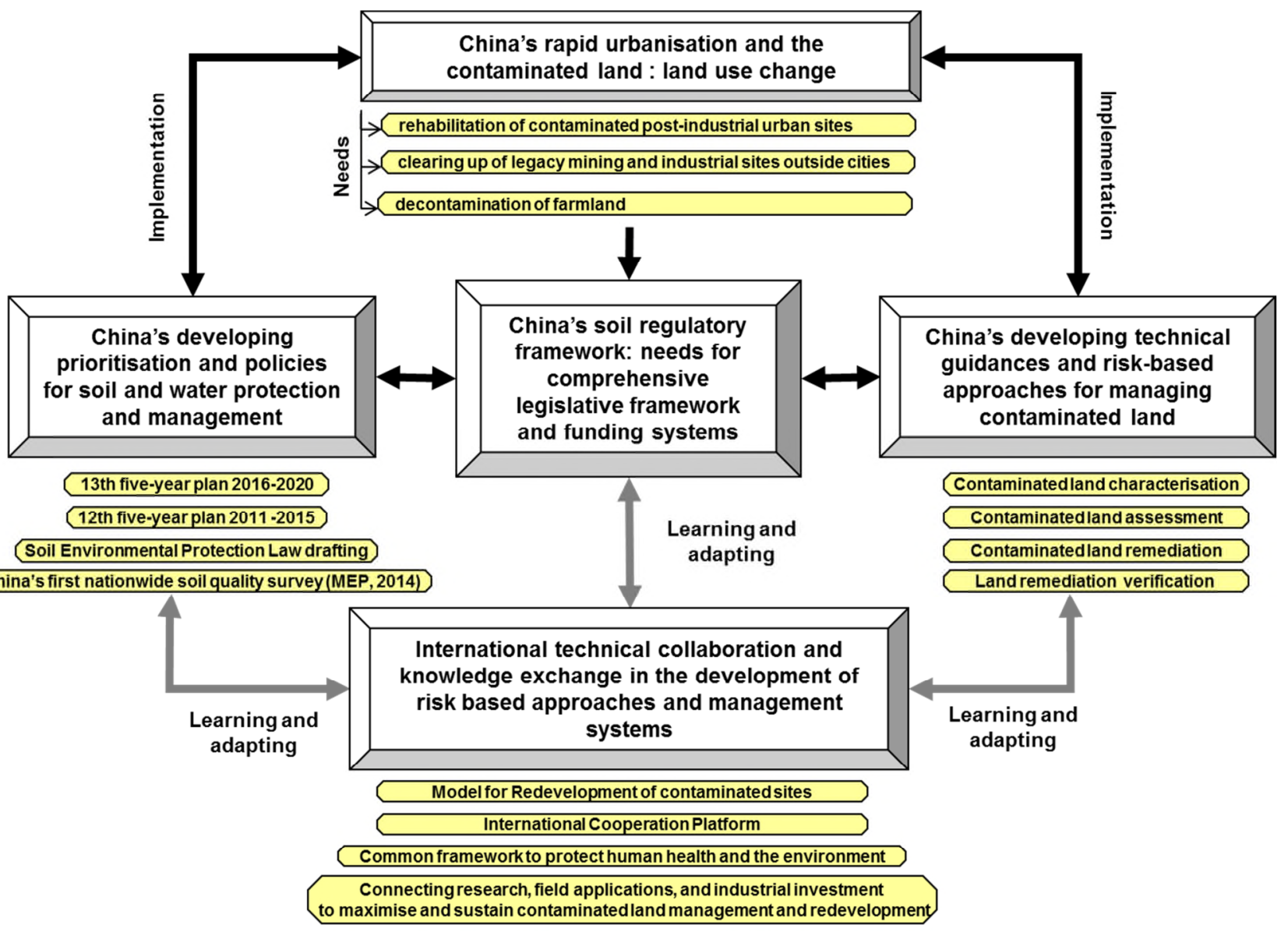

312 Figure 1: Overview of China's soil and groundwater management challenges and 313 opportunities for technical collaboration and knowledge exchange 


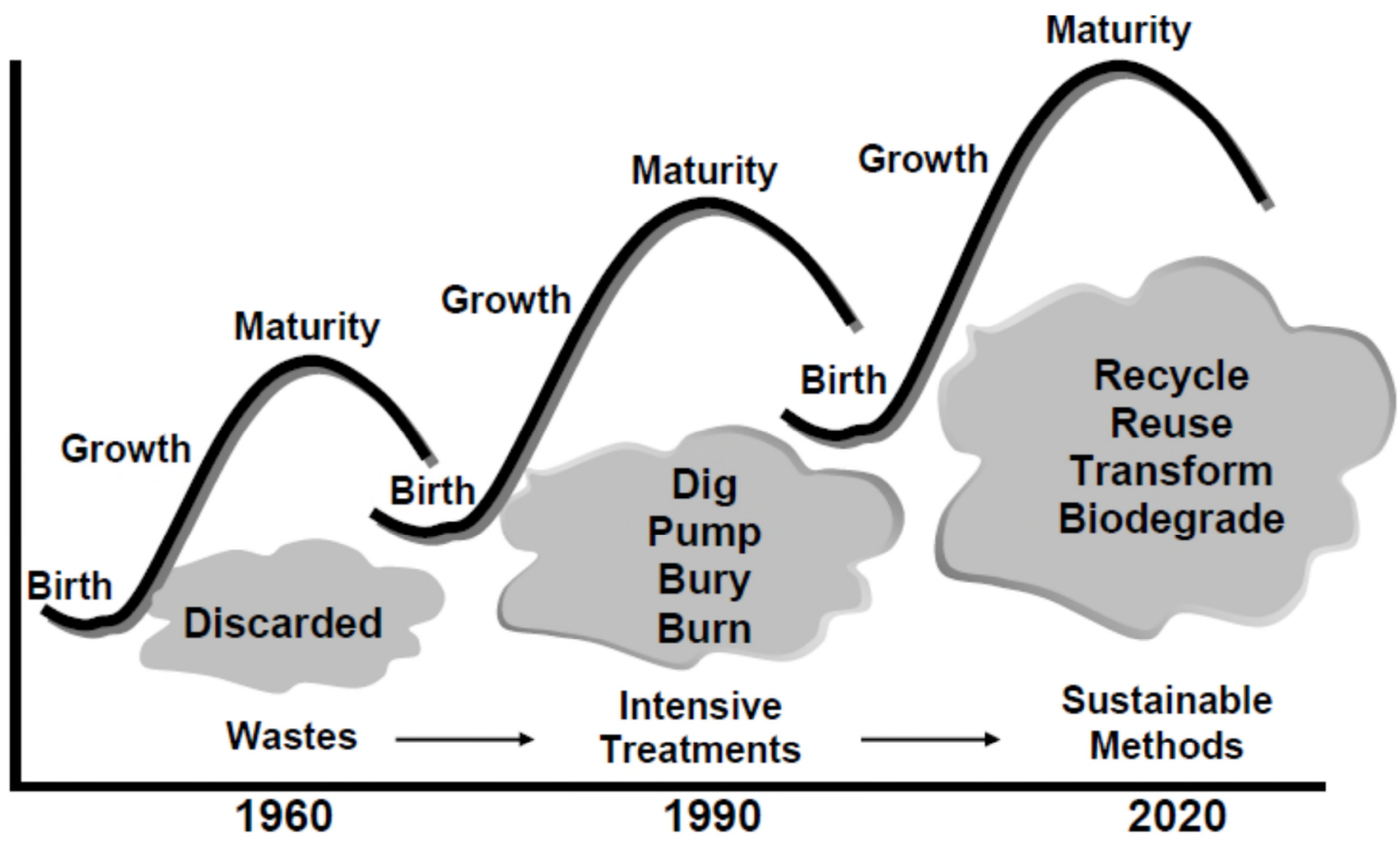

Figure 2: Evolution of contaminated land management (reproduced from Ellis and Hadley 2009)

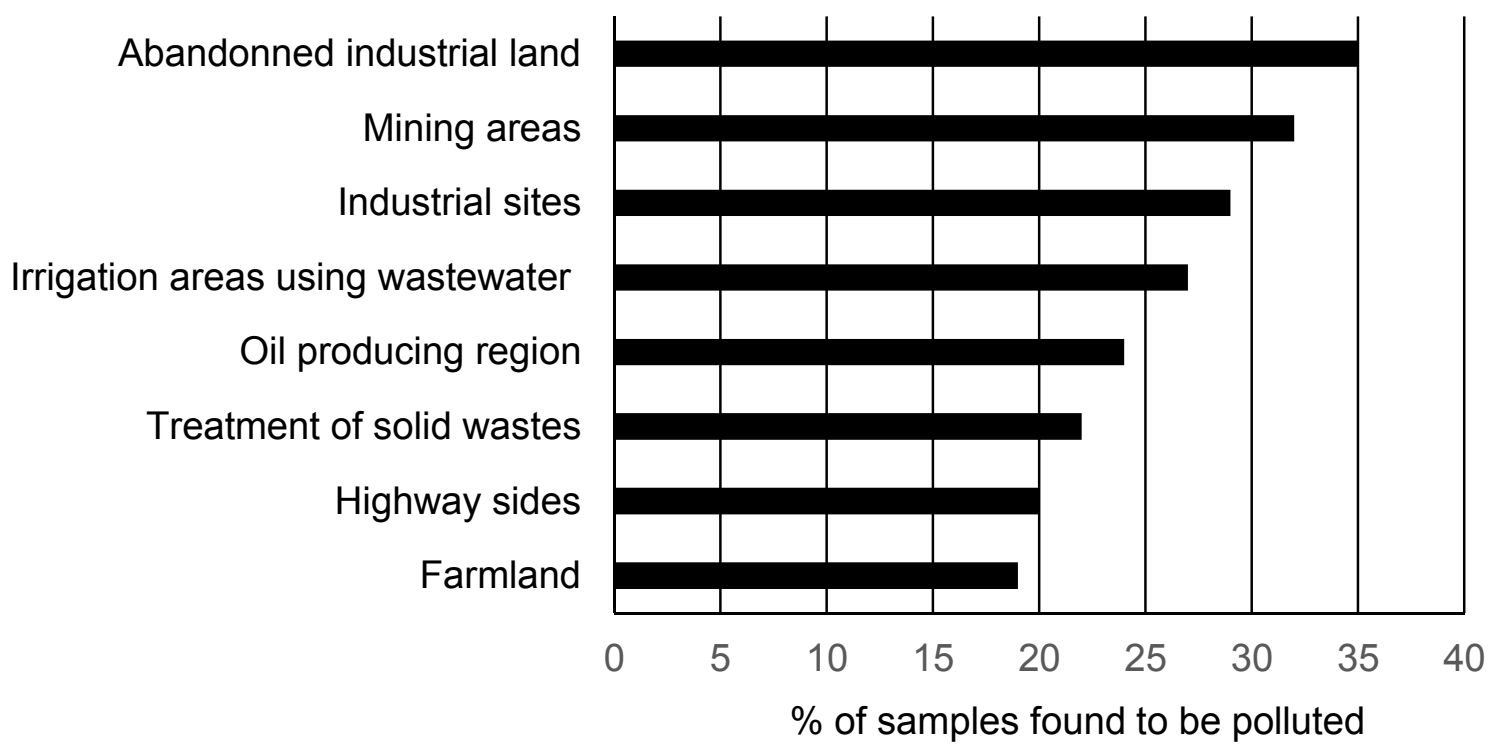

Figure 3: Percentage of soil samples found to be polluted according to land use (adapted from 322 MEP, 2014) 
324 Table 1: Main pollutants in soil and groundwater identified from the China national soil

325 pollution survey (adapted from MEP and MLR, 2014)

\begin{tabular}{|c|c|c|c|c|c|c|}
\hline \multirow{2}{*}{$\begin{array}{l}\text { Pollutant } \\
\text { type }\end{array}$} & \multirow{2}{*}{$\begin{array}{l}\text { Background } \\
\text { level }(\mathrm{mg} / \mathrm{kg})\end{array}$} & \multirow{2}{*}{$\begin{array}{l}\text { Exceedance } \\
\text { of surveyed } \\
\text { samples (\%) }\end{array}$} & \multicolumn{4}{|c|}{$\begin{array}{c}\text { Breakdown of exceeding surveyed samples } \\
\text { by extent of exceedance }(\%)\end{array}$} \\
\hline & & & $\begin{array}{c}\text { Minor } \\
(1 x-\leq 2 x)\end{array}$ & $\begin{array}{c}\text { Mild } \\
(2 x-\leq 3 x)\end{array}$ & $\begin{array}{l}\text { Moderate } \\
(3 x-\leq 5 x)\end{array}$ & $\begin{array}{l}\text { Severe } \\
(>5 x)\end{array}$ \\
\hline \multicolumn{7}{|l|}{ Inorganic } \\
\hline Cadmium & 0.2 & 7 & 5.2 & 0.8 & 0.5 & 0.5 \\
\hline Nickel & 40 & 4.8 & 3.9 & 0.5 & 0.3 & 0.1 \\
\hline Arsenic & 15 & 2.7 & 2 & 0.4 & 0.2 & 0.1 \\
\hline Copper & 35 & 2.1 & 1.6 & 0.3 & 0.15 & 0.05 \\
\hline Mercury & 0.15 & 1.6 & 1.2 & 0.2 & 0.1 & 0.1 \\
\hline Lead & 35 & 1.5 & 1.1 & 0.2 & 0.1 & 0.1 \\
\hline Chromium & 90 & 1.1 & 0.9 & 0.15 & 0.04 & 0.01 \\
\hline Zinc & 100 & 0.9 & 0.75 & 0.08 & 0.05 & 0.02 \\
\hline \multicolumn{7}{|l|}{ Organic } \\
\hline $\mathrm{HCH} 1$ & 0.05 & 0.5 & 0.3 & 0.1 & 0.06 & 0.04 \\
\hline DDT2 & 0.05 & 1.9 & 1.1 & 0.3 & 0.25 & 0.25 \\
\hline $\mathrm{PAHs}^{*}$ & - & 1.4 & 0.8 & 0.2 & 0.2 & 0.2 \\
\hline
\end{tabular}

$326{ }^{1}$ Hexachlorocyclohexane $(\mathrm{HCH}),{ }^{2}$ dichlorodiphenyltrichloroethane (DDT) and ${ }^{3}$ Polycyclic

327 aromatic hydrocarbons (PAHs) are among the most frequently detected organic contaminants

328 that exceeded the soil standards. ("number" $\mathrm{x}=$ order of times exceedance occurred) 